University of New Mexico

UNM Digital Repository

University Libraries \& Learning Sciences Faculty and Staff Publications

Scholarly Communication - Departments

2-13-2017

Teaching with the Framework: a Cephalonian Approach

David A. Hurley

Robin Potter

Follow this and additional works at: https://digitalrepository.unm.edu/ulls_fsp

Part of the Scholarly Communication Commons 


\section{Teaching with the Framework: A Cephalonian approach}

\begin{tabular}{|r|l|}
\hline Journal: & Reference Services Review \\
\hline Manuscript ID & RSR-07-2016-0044.R1 \\
\hline Manuscript Type: & Original Article \\
\hline Keywords: & $\begin{array}{l}\text { Library instruction, Information literacy, ACRL Framework, Cephalonian } \\
\text { Method, Engagement, one-shot }\end{array}$ \\
\hline \multicolumn{2}{|l}{} \\
\hline
\end{tabular}

\section{SCHOLARONE ${ }^{m}$ \\ Manuscripts}




\section{Abstract}

Purpose: This paper provides academic instruction librarians with a model for integrating concepts from the ACRL Framework into "one-shot" library instruction sessions without losing the practical experience of searching the library resources.

Design: The authors adapted the Cephalonian Method as the structure of our first-year library instruction sessions for an English Composition class. The sessions were re-designed to emphasize the core concepts of information literacy, while incorporating active learning activities and discussion.

Findings: The authors found the Cephalonian Method to be a useful structure for incorporating aspects of the ACRL Framework into our first-year library instruction program. The call-andresponse format fosters conversations and leads seamlessly into hands-on activities. When used as part of "flipped" instruction, the Cephalonian Method allows instructors to engage both students who have completed the online portion and those who have not.

Practical Implications: This paper offers librarians practical ideas on incorporating the information literacy concepts outlined in the ACRL Framework into one-shot instruction sessions.

Originality/value: With the recent adoption of the Framework for Information Literacy for Higher Education by ACRL, there is a need for practical examples of how to incorporate the frames into existing library instruction programs.

Keywords: Information Literacy, Library instruction, ACRL Framework, Cephalonian Method, one shot, engagement 


\section{Introduction}

There is often a disconnect between what librarians intend to accomplish through information literacy instruction and the content of library sessions in practice (Kerr, 2010). The Association for College and Research Libraries (ACRL) has recently adopted the Framework for Information Literacy (2015), providing an opportunity to reflect on both content and teaching methods in library instruction. The authors embraced this opportunity at the University of New Mexico when we joined the faculty as Learning Services Librarians in early 2015. The concern was that we not under-emphasize the big ideas of information literacy in the service of introducing the basics of using library databases (Oakleaf, 2014).

During the Spring 2015 semester we developed a new approach to teaching one-shot library sessions in our first-year instruction program. Our new approach has students explicitly engage with the core ideas outlined in the Framework, while still giving students hands-on experience with library resources. Our goal was for students to begin to reflect broadly on how scholars think about information, separate from the specific knowledge and abilities necessary for the completion of any particular assignment. Developing this new approach also allowed us to address problems we had identified in the previous approach to first-year library instruction, such as repetition of content across multiple classes, timing of the library session in the semester, and relevance of the research project assigned in the class to the content of the session.

In this paper, we discuss how we reconceived the one-shot library instruction sessions in an English Composition course, English 120, the core of our first-year instruction program. Specifically, we share how we adapted the Cephalonian Method (Morgan \& Davies, 2004) as a way of structuring the session to emphasize the core concepts of information literacy without losing the practical experience of searching our resources. Because our sessions are offered 
either as stand-alone or as a flipped session, we also discuss how our approach addresses challenges specific to flipped classrooms.

\section{Background}

The first-year library instruction program at the University of New Mexico consists of one- (or two-) shot sessions in courses typically taken during students' first few semesters. However, most of these courses can be taken in any order and none are required of every student. This means scaffolding across courses is not possible.

Prior to 2015, these sessions were typically framed as orientations to the library and taught skills to meet an immediate need for an assignment. Though there was often some effort to address information literacy in a more conceptual way, including piloting flipped sessions in Fall 2014, the bulk of each session consisted of having students become familiar with using a specific library database and aware of the various ways to connect with librarians for further assistance.

Because our sessions were designed to meet an immediate need for an assignment, there was, necessarily, a great deal of overlap across sessions for first-year courses: the same research skills and resources are needed for typical assignments in English 120, Public Speaking, and most other 100-level general education courses. Additionally, because these courses can be taken in any order, any given session could have students for whom the session was their first library instruction and others who had already attended several instruction sessions. Sometimes, students enrolled in multiple courses with library instruction simultaneously wound up in multiple library sessions in a short period of time. Indeed, we know of at least one case where the same student was in three library sessions for three different courses in a single week. 
While librarians made informal efforts to focus on different general-purpose resources in sessions specific to different courses (for example, EBSCO's Academic Search Complete in one course, and a ProQuest database for another) the sessions were necessarily somewhat redundant. Through both formal and informal feedback, we knew many students assumed they would know everything in our session because they had already been to a previous one. We also heard of students requesting permission from their course instructors (sometimes successfully) to skip the required library session because they had already attended a library session with another class. While covering some of the same information in multiple sessions is unavoidable in our context, and not completely undesirable, we did not want students to feel they were wasting their time.

The prior approach to framing library instruction in response to an immediate need had two additional drawbacks as well. First, the sessions were often scheduled at a point other than the point of immediate need, undermining the frame of the class. It is hard to convince students of the value of database demos relating to an assignment they have not been given yet. With over 100 sessions a semester, and limited space and staffing in the library, this was logistically unavoidable.

The second and arguably greater drawback was that for many of the research assignments in 100-level courses, their existing Google search skills would serve them well enough. Even assignments explicitly requiring "a peer-reviewed article related to your major" are more efficiently completed, given the often limited familiarity of the disciplines to first-year students, using Google: a search for peer-reviewed political science article in Google produces better results than the same search in Academic Search Complete.

These issues are not unique to the University of New Mexico. Alas, they will likely be familiar to instruction librarians at many institutions, both large and small. While the main 
purpose in reconceiving our instruction program was to make information literacy concepts (rather than specific tools or skills) the focus of the session, we took the opportunity to address these other issues as well.

The first session we reworked was for English 120. With over 60 sections in the Spring semester and an established requirement of at least one library session, this course is the core of our first year instruction program. We decided to make the content for these sessions independent from any assignment, using the ACRL Framework as inspiration for the concepts we would cover. This allowed us to provide meaningful sessions at any point during the semester. Course instructors have the option of adding a second session to have librarians work with students on a specific assignment.

To reduce redundancy across sessions, we decided to emphasize a different frame (or combination of frames) from the ACRL Framework in each course. For English 120, we chose to emphasize the frame Information Creation as a Process. We focused on this frame for a variety of reasons, but in large part because it fit well with one of the learning objectives of the course: "analyze and describe the writing and research conventions of an academic field in order to understand the different ways of creating and communicating knowledge." (http://englishold.unm.edu/resources/documents/student-learning-outcomes-handbook.pdf)

We also eliminated most of the orientation content (e.g., study spaces, printing services, and branch hours) from the English 120 session, devoting virtually all of the allotted time to exploring information literacy concepts. This approach has its own drawback: in a 50- or 75minute class students need to engage with the topic almost immediately if the session is to be at all effective. Librarians at University of New Mexico had previous success engaging students 
using the 'Cephalonian Method,' so we adapted this method as a way to get English 120 students engaged quickly during the library session.

\section{Literature Review}

The Cephalonian method was originally used in libraries by Morgan and Davies $(2004,2008)$ as a replacement for library tours for large-scale library orientations (or, to use their term, 'inductions'). The method, in brief, involves distributing pre-printed questions for students to ask during the session in a somewhat unpredetermined order. Additionally, Morgan and Davies pair each question with an image projected on a screen, and have music playing during the session, creating a multi-media experience. The questions are printed on colored cards, with questions of the same color forming groups. The instructor can ask for red questions first, for example, and then yellow questions, but within the red group questions can be asked in any order. The grouping of cards provides structure to the session, while the unpredictability within each group makes the session more spontaneous. Cephalonian questions typically are phrased in ways intended to create a sense of fun. For example, the Morgan and Davies question about printing services is written as “'My Mum has e-mailed me a photo of Miguel, my pet iguana. Where can I print him out?"' (2004). This sense of fun, combined with student participation and the sense of spontaneity, resulted in sessions with very positive student feedback.

The effectiveness of the Cephalonian method at engaging students has been replicated in a wide variety of other institutions, both in library orientations (e.g. Barnes and Walton, Brown and Hart, 2009; Castle and Acred, 2010; Jones et al., 2007) and as an icebreaker at the start of an instruction session (Hegarty, 2008). 
While the basic technique of distributing pre-printed questions to students is common across all instances, there is considerable variability in other aspects of the implementation. While Morgan and Davies (2008) considered an accompanying slideshow an essential part of the method, others have dropped the multimedia aspects altogether (Castle and Acred, 2010; Wells, 2013).

The approach to phrasing the questions, while generally aiming to create fun questions, also varies. Wells (2013), working with music majors, phrased her questions in a way to be entertaining to that audience. For example, one question she used was "I really enjoy listening to Shostakovich symphonies at 3 am because they put me right to sleep. Are there any streaming music resources other than Pandora or Spotify that I can use?'” Vossler (2011), on the other hand, chose a theme unrelated to the content of the session: pirates. "What be thar to do if some mutinous sea dog has checked out the book I want?"

For the session to work, the questions must be asked in an order that makes sense. While some create a set order for the questions (Castle and Acred, 2010; Wells, 2013), more commonly questions are grouped by specific databases (Vossler, 2011), formats (i.e., questions about books and the catalog, questions about articles and databases (Galloway, 2010), or types of interactions with the library, e.g. questions about finding items vs. questions about services and facilities (Morgan and Davies, 2004).

Given the adaptability of the Cephalonian Method and its well established success at engaging students in library sessions, we decided it would be a good match for our English 120 sessions.

\section{Developing the Cephalonian Session}


Because the Cephalonian method was developed to introduce library services in the context of an orientation or as a brief ice-breaker, we needed to adapt the method for use as the structure for an entire class session. While our sessions always take place in computer classrooms with screens and speakers, we decided not to incorporate music or slides in our presentation. We felt given the small class size - English 120 classes are capped at 24 students - the multi-media aspect of the Cephalonian Method, so effective with large groups, would actually hinder developing rapport with the students.

We also needed to rethink how Cephalonian questions would work in the session. Though our library resources were no longer the focus of the session, we still planned to incorporate hands-on searching of our catalog and databases, and to be able to include other types of active learning activities as well, within the Cephalonian question and answer structure. We therefore created guidelines for developing Cephalonian questions for use in our session:

- Determine what to cover.

- Create questions from a student perspective.

- Add fun by exaggerating some element of the question or response.

- Organize the questions into appropriate groups.

For our 50 or 75 minute sessions we typically have eight to ten questions.

\section{Determine what to cover}

Since we opted to use the frame Information Creation as a Process as our main focus, we wanted to have students explore the idea that different formats are created differently, have different kinds of information, and serve different purposes. Additionally, our students should recognize the difference in approach to research in scholarly contexts. 
Below are the four main ideas we identified:

- Academic research is fundamentally different from the casual research we do every day. Typically, in academic research, we don't expect to find information which directly answers the research question.

- There are different ways information is produced and published, and they are useful for different purposes. Depending on what one is trying to understand, one may need a mix of scholarly articles, books, news sources, trade publications, and/or other formats.

- Different search tools are more or less effective for finding different types of resources. Google is good for some formats, but poor for others. Business considerations, as well as technical issues, make much content invisible to public search engines.

- Research isn't easy. Frustration is normal. The library has people who can help.

We agreed the new English 120 sessions should focus on discussions and activities to encourage student engagement with these ideas.

Ask questions from the students' perspective

We knew why we wanted students to gain fluency with the "Information Creation" frame, but why would they think they need it? Asking the question from the student perspective is key to the success of the Cephalonian method, whether covering big ideas or policy basics. This is especially obvious when planning library orientations: while it might be useful for students to know how many books they can borrow at a time, the topic will not resonate with this phrasing: What quantity restrictions are specified in the circulation policy for items borrowed by my patron type?

To address this issue, for each concept we imagined a scenario in which this information would be important to our students. In the above example, perhaps the student is working on two 
papers simultaneously for two different classes and so expects to require more books than usual. From that perspective, we would rephrase the question to:

I've got research papers due in two classes. Will I be able to borrow all the books I need?

This is a fairly simple process for questions about library policies and services, but it can be challenging for more conceptual material relating to the frame information creation as a process. However, this difficulty makes the exercise especially important. By understanding how students might approach the topic, we are in a better position to frame the content in a more relevant way. Using the Cephalonian Method makes this reflection unavoidable. Conversely, if we cannot formulate a question about the content from the students' perspective, we need to reassess whether it belongs in the session at all.

For our English 120 sessions, we considered in what situation our students are most likely to encounter the idea that the format of information matters. For many, it is in assignments which require them to use peer-reviewed sources or forbid Wikipedia or 'online sources.' Two examples of questions related to this idea are:

Question 1: Why do some professors think Google and Wikipedia are bad?

Question 2: What do professors mean when they say an article isn't scholarly?

Neither of these is (yet) a terribly compelling question, but it addresses the topic we wish to cover from a student perspective. By making the questions more fun (the third guideline), we will also make it more engaging.

Add fun by exaggerating the scenario

Embedded in Question 1 above is the suggestion that students and their professors disagree about the usefulness (or quality) of Google and Wikipedia. Students may see these 'rules' forbidding 
the most accessible sources as arbitrary restrictions. By rewriting the question to exaggerate this perspective we are able to address this assumption explicitly. The question becomes:

I get it. Everything I find in Google or Wikipedia is bad, everything I find in the library is good. Can I leave early?

Phrasing the question this way also addresses head-on the not uncommon expectation that the library session itself is going to be a waste of time.

Question 2 can be rewritten as:

I'm writing a paper about waxing and I found this great article from Cosmo, but my professor said that Cosmo is not a "Scholarly Journal." What does that even mean?

This question highlights a danger with trying to make the questions fun. We do not want to give the impression that we are making fun of students. Nor do we want students to be uncomfortable asking any of our questions. However, if handled well by the librarian, this question is useful for highlighting that it is not the topic itself which is scholarly or not, but how it is investigated.

Comparing scholarly and non-scholarly sources for this topic gives insight into the different purpose of these different formats and the different kinds of information found in each Organize the questions into appropriate groups

Maximizing the flexibility in the order of the questions creates a sense of spontaneity in our sessions. However, we also realized that some questions rely on information discussed in response to earlier questions. Creating broad groups of questions, differentiated by the color of the paper on which they are printed, allowed us a balance of spontaneity and structure. We also decided to encourage variety within question groups by mixing questions which lead to demos or other activities with ones that can be answered quickly.

\section{Additional Considerations}


By following these guidelines, it is relatively simple to create questions for any class session. The questions can be customized depending on current events, the class assignment, or the interests of the librarian. Indeed, while the librarians teaching English 120 share questions, there is no definitive question set. Because the sense of fun is essential to the Cephalonian Method, it is important for each librarian to bring their own personality, emphasis, and sense of humor to the session through the questions they use. Selecting, regrouping, and creating new questions become important elements in preparing for the session.

\section{Running a Cephalonian Session}

Below is an example of how the method might be implemented in a one-shot English 120 session held in a library computer classroom. This should not be taken as exactly how we run our sessions - as mentioned above, we experiment constantly with new questions, different groupings, and alternative activities - but it gives a feel for how our sessions are run.

First Question Group: Setting the Stage/Library Policies (Red Cards)

We have found it helpful to begin sessions with a few questions which can be answered quickly to establish the question-and-answer format before moving to questions involving searches or other activities. We typically start with some basic questions about library policies. Above, we gave an example of a policy question: I've got research papers due in two classes. Will I be able to borrow all the books I need?

We exaggerated the scenario, resulting in this form of the question: If I've checked a book out for this class, and need one for another class...I guess I have to finish the first book before I can borrow a second one, right? 
We ask students to guess how many books can be checked-out at once. They typically start at five or ten, and are surprised to learn the true number: 200. It is a quick and easy warmup, and the element of surprise gets the students engaged. It also provides us an opportunity to highlight that our policies and services are designed to facilitate scholarship, rather than protect our collections, a theme we touch on with all of our introductory questions.

Second Question Group: Searching the Catalog (Orange Cards)

After two or three quick questions, and still early in the session, we ask for an orange question. The orange cards group contains just one question, designed to lead into a search for a book in the catalog.

Our reasons for having them do a catalog search are several: a hands-on activity engages students in a different way than the questions and answers do; to have them become familiar with using the catalog; and, most importantly, it serves as an entry point for the more conceptual ideas we address in the session.

Because our primary search box searches a discovery layer which includes Worldcat as well as our databases, our catalog behaves differently than many students expect. By default, the results list in our catalog includes titles we don't actually have in our collection. We use these quirks to our advantage in the session by having students do a search which brings up many different formats -tying back into our frame for the class- and shows off the many ways to filter or limit a search (touching on the frame of Searching as Strategic Exploration).

Because interpreting the results list can be overwhelming we have students do a knownitem search for a title we think many students will be familiar with. This way, they can recognize with relative ease whether any given result is a match. We also choose titles not owned by the library. Because ownership is given preference in our search results, this results in a result set 
which includes the correct title, but -depending on the search strategy used- is not on the first page of results.

While there are many titles which work for this search, the two titles we use regularly are the Dr. Seuss classic Green Eggs and Ham (Seuss, 1960) and Alvin Schwartz's very popular Scary Stories to Tell in the Dark (1981). When using Schwartz's work, our question is phrased this way:

I heard that the book Scary Stories to Tell in the Dark is so scary that a lot of people want it banned! Does UNM have it?

When this question is asked, we have the students try to determine the answer by searching our catalog at their workstations while we walk around the room and observe their search strategies.

By far, the most common way students search is by entering the title, without quotes, into the "Quick Search" box on the library's website. This retrieves hundreds of results which match the keywords, but are not the desired book. For example, Alvin Schwartz's In a dark, dark room, and other scary stories (1984) is among the first results. The first result with the correct title is an article from the Newsletter on Intellectual Freedom ("Scary Stories to Tell in the Dark.", 1995). This result allows us to highlight how to analyze the search results for format - students often think they have found the item itself until they dig a little deeper. It also provides a chance to discuss intellectual freedom with regard to library services and collections, and give context to the challenges to the book referenced in the question.

For Green Eggs and Ham, we use this version of the question:

Can you recommend any books about using peer pressure to get people to eat weird food, like, um, multi-colored pork products? 
We pretend to struggle to remember a brilliant case-study on this topic written by a famous “doctor." It doesn't take long for our students to figure out the title we mean. Again, our library does not own Green Eggs and Ham, so, while entering the title in the library's search box results in more than 1200 results, the correct result is not on the first page. While many students stop at the first page, a few do find the book using search limits, or different search strategies.

With either version of the question, we give the class two or three minutes to find the title while observing their searches. At the instructor station, we redo the unsuccessful keyword search tried by most students, projecting the results onto a screen. We highlight the total number of results and the absence of the correct one. We then ask students who were successful to explain what they did differently. Typically, there are two or three successful strategies which students in the class share. These are demonstrated by either the student or the librarian at the instructor station. During these demos we highlight search techniques such as the use of parentheses, relevant filters, and introduce the disconnect between how we think of our search and how the catalog interprets our query.

Finally, the unexpected fact that our catalog lists things we do not own gives us a chance to explain the philosophy of using the catalog for discovery rather than as an inventory. This provides an opportunity to explain interlibrary loan as well.

The Cephalonian question asking about using peer pressure to get people to eat multicolored pork products has an additional use as well: the subject headings for Green Eggs and Ham include "Food preferences -- Juvenile fiction." (https://unm.on.worldcat.org/oclc/184476) Highlighting this subject heading on the screen, we can point out that if we were actually researching the use of peer-pressure in getting people to eat weird foods, the "juvenile fiction" heading would indicate this title is not the brilliant case study we thought it was, while "food 
preferences" would, in fact, be a useful phrase for searching the topic. For sessions where the students do not yet have topics they are researching, peer-pressure and food preferences can be used as the example topic throughout the session.

Third Question Group: Core Concepts (Yellow Cards)

Having introduced the library and given the students a chance to search the catalog, interpret their results, and refine their strategy, we move into the core of the session: exploring the idea of information creation as a process, and the impact format has on where and how they will find and use information.

We use different formats (news and magazine articles, encyclopedia entries, scholarly articles, social media posts, etc.) to explore differences in the purpose of each publication, and therefore the differences in the kind of information they contain. From there, we examine the work done by the authors in order to write the article and look at the different quality control mechanisms (e.g., editorial or peer-review) typically used in each format as well as the distribution models (e.g., free on the web versus paid subscription).

Some of the questions we've used to address these topics are:

- I get it: Everything I find on Google and Wikipedia is bad, everything I find in the library is good. Can I leave early?

- Why do we have to ask YOUR questions all the time? Why can't we ever ask our own questions?

- I'm writing a paper about waxing and found this great article from Cosmo, but my professor said that Cosmo is not a "Scholarly Journal." What does that even mean?

- So, um, how do we actually find articles? 
Of course, students can ask these questions in any order within the group, so how each question is answered will depend on the order dynamically created in the session. For example, the question how do we actually find articles leads into a database demo. If it is asked first, just after the catalog searching activity, the demo is very brief. Students navigate to a general purpose database like Academic Search Complete, do a search and navigate to the full text of an article. In this case, the subsequent questions are used to refine the search and explore the results. If, instead, this question comes later within the yellow group, the demo can be a hands-on activity where the students apply what they learned from answers to the other questions.

The question about the student using an article about waxing from Cosmopolitan, as discussed earlier, can be problematic. While the question always gets a laugh, the laugh comes from a sense that the topic and the source are inappropriate. The class is laughing at the stupidity of the student. When we use this question, we make sure the card goes to an obviously outgoing student who, we hope, won't be embarrassed at asking the question. So, why use this question, given its problems? Because in answering the question, we can challenge some assumptions about what makes a source (and a topic) appropriate. First, we talk about what kind of magazine Cosmopolitan is, and that it isn't a poor choice for certain kinds of information about waxing specifically, information on how to do it, and what the trends are. This can lead into an activity comparing different formats. This can be a whiteboard-based activity if it is asked before the database demo, or can involve filtering by publication type within a database. If handled as a database demo, the initial results are related to astronomy, highlighting again the disconnect between the concept we are searching for and how the system processes our search.

Once an additional term (such as hair) is added to disambiguate the concept of waxing, comparing results from newspapers, magazines, academic journals, and trade publications is 
illustrative of the different kinds of information found in each format. Comparing results from Google with those from Academic Search Complete can also be interesting, if this question is asked after the Google/Wikipedia question. As expected, the magazine results focus on "howto" type articles, and on the continued popularity of waxing. Scholarly articles, on the other hand, present several different kinds of research related to waxing, from medical research to research related to gender, attitudes about sex, and other social science topics. So, while many students originally think waxing is an inappropriate topic, they discover any topic can be approached in a scholarly way, while also seeing the clear differences between various information formats.

The question asking “[w]hy can’t we ever ask our own questions” exists primarily to be answered quickly, e.g., “[B]ecause I haven’t memorized the answers! No no, of course, if you have a real question, please ask it." This provides a breather in the midst of several questions requiring longer answers. It is also important, as the material covered gets more complex, to let students know that authentic questions (as opposed to the ones provided on the cards) are welcomed.

The answer to the "[e]verything I find on Google and Wikipedia is bad, everything I find in the library is good" question depends very much on the order in which it is asked. In any case, we emphasize that our point is not on good vs bad - acknowledging the library contains plenty of 'bad' sources, and many 'good' sources are discoverable via Google - but rather the difference between researching to satisfy personal interest, and research to construct a scholarly argument. We also mention the economic aspect of Google searches - you can typically only access information which is freely available or ad-supported via public search engines - and 
therefore Google and the library's search tools are good at finding different kinds of information, in different formats.

Fourth Question Group: Helpful Services (Green Cards)

The last group of Cephalonian questions can be answered in-depth if there is time available, or quickly if need be. These questions allow us to highlight especially helpful features or services available to our students:

I hate having to cite my sources. Why, why, why do we have to this? Time permitting, the 'why' part can be answered in depth. Otherwise, the answer can focus on the resources available to make creating citations less onerous, such as the citation generators in our catalog and most databases, and citation style guides available online.

\section{What if I get completely lost and can't find anything on my topic?}

Again, time permitting, there can be some discussion on how to refine a topic into something for which appropriate resources will exist, and why no resources will exist for some topics - e.g., too specific or for some reason unknowable. Typically, we use this question primarily to highlight the various means by which students can get help from reference librarians. If this question comes last, it serves as a nice wrap up to the session. If it comes before the citations question, we remind students that librarians are a resource for helping with citations, and end with the idea that we are here to help.

\section{Cephalonian Method and the Flipped Classroom}

Beginning in Fall of 2014, our library has offered the English 120 course instructors the option of using a flipped (see O'Flaherty and Phillips, 2015) version of the library session. The instructors assign students an online tutorial that involves viewing a few brief videos, answering 
short-answer and multiple choice questions, and searching Academic Search Complete. The tutorial introduces the idea of information creation as a process which can be recognized, in part, through format, as well as covering topic development, search strategies, and using library databases.

Requiring students to do work in advance of a one-shot library session in theory maximizes the use of class time. In practice, it introduces a problem familiar to those who teach credit-bearing classes: a significant portion of students will not have completed the work. In our flipped English 120 sessions we find the completion rate for the tutorial varies widely by class. Looking at how long students spent on the tutorial also reveals that some students click through the tutorial rapidly, answering our questions without actually completing the component activities.

This presents two problems in the classroom. The first is in presenting the content itself. Either we run the session with the expectation the students have been exposed to the content in the tutorial, and thereby leave part of the class completely lost, or we run the session treating the information as new, effectively wasting the time of those students who completed the tutorial. The second problem is the affective dimension of the classroom dynamic. When students come to a library session feeling they need to hide that they did not complete the assignment, engaging them is considerably more difficult. Often, students in these sessions (presumably the ones who did not complete the tutorial) exhibit an active disengagement - no behavior of any kind, positive or negative, that will draw attention to themselves.

Using the Cephalonian method addresses both of these problems. Because we give them the questions to ask, rather than asking them for answers, students who did not complete the tutorial are able to participate in class and, to some extent, get up to speed on what the tutorial 
covered, while students who did complete the tutorial are able to connect what they learned with the activity or information they encounter in the session

The questions we use (or sometimes just the way we answer them) change for a flipped class. For example, we often skip the library policy questions that were Group One in the previous example. In most classes, these questions are a low stakes way of breaking the ice and establishing the Cephalonian Method. In a flipped class, students may think this is material they were expected to have learned in the tutorial, resulting in an outcome quite the opposite of a successful ice-breaker. Instead, we open with a question like "I get it: Everything I find on Google and Wikipedia is bad, everything I find in the library is good. Can I leave early?" Opening with a question relating to the purpose of the session allows students to engage whether or not they completed the tutorial.

In our response to this question we briefly discuss the relative strengths and weakness of library search tools and free public search engines, reviewing some of the content from the tutorial on formats in the process.

The second group of questions asks about the tutorial. For example, "[t]hat keywords video made no sense. Why can't I just type in what I'm looking for?" This question references a video in the tutorial about choosing search terms. It can lead into, for example, a keyword generation activity or a database search exercise comparing results for searches on the same topic using different search terms.

Below are a few additional examples of questions we have used as part of the flipped class:

- The tutorial said scholarly journals are for original research. Wikipedia doesn't allow original research. What's the deal with original research? 
- The formats video said look at newspapers for the latest news, and scholarly articles come years later. But in the quiz, I said a new treatment for HIV would be in a newspaper, and I got it wrong. Huh?!

- The tutorial was super helpful! I got thousands of results when I searched! I only need four, so I grabbed the first four. Now I just have to find some good quotes and I'm done. Four-Point-Oh, here I come, right?

\section{Challenges in Using the Cephalonian Method}

In their initial article, Morgan and Davies (2004)(2004) reported that occasionally cards are "surreptitiously withheld" by students, and this has occasionally been our experience as well. However, as far as problems go, this one is actually relatively minor. Morgan and Davies emphasize that a student with a card may pass the card to another student if they are unwilling to ask it, an approach we have used with success as well. Another approach we use is to give every student a question card. In this case, each question is duplicated two or three times, though only asked and answered once. While neither method completely eliminates the possibility of a question not being asked, in practice, it is very rare. When it does happen, the librarian needs to be flexible, realize a question was skipped, and work the content into answers to other questions. Another problem revealed itself with one of our favorite questions: "I get it. Everything I find on Google and Wikipedia is bad, everything I find in the library is good. Can I leave early?" This question gets to the heart of the disconnect between what students think they are being taught in a library session, and how we actually want them to think about information sources. However, the librarian has to think quickly when the student holding that question raises a hand and asks only 'Can I leave early?' 
When this first occurred, we thought it happened because of the length of the question. However, it has happened even with very short questions using a similar construction. The issue seems to stem from a literal interpretation of what constitutes the question. While it is effective to ask the student to read the entire card, doing so breaks character, and may embarrass the student. A better approach is to respond to the question in a way that provides the context: "You want to leave early? Oh, I bet you think all I'm going to tell you is 'Don't use Google.' Have any of you heard that before?"

Another problem is the surprising difficulty of fully anticipating issues with the order in which questions could be asked. As an icebreaker, this is less of a problem, as each question is distinct. When used to structure an entire session, it is important for the questions to build on each other. It can be tempting to make the order rigid, with numerous groups of one or two questions. The sense of spontaneity arising from the unexpected order is worth the trouble, however, and with a bit of creativity and adaptability -and a lot of confidence on the part of the librarian- ordering problems can be mitigated on the fly during the session.

The most troublesome problems result from the use of humor. While humor is an important part of why the Cephalonian method is so effective at engaging students, it can also backfire. The scenarios in the questions can have a sense of the ridiculous about them, but the students should not feel they are being made fun of, either individually or as a group. If the librarian makes themself the butt of the joke it also interferes with student engagement, perhaps due to the us/them dynamic which is established. Also, too much comedy can be tiring for the audience. While over-the-top silliness may be effective in a short ice-breaker or orientation, we have had better success in our sessions with slightly exaggerated scenarios in the questions, and a balance between humorous and 'straight' answers in the responses. 


\section{Outcomes \& Conclusions}

Feedback from students via an end of session survey and from the course instructors via an end of semester form has been overwhelmingly positive. At least as importantly, our own subjective assessment of how successful we are at engaging students with the material of the session is that we are far more effective using the Cephalonian method, especially if the students do not have a current research project they are working on.

The one major limitation of the Cephalonian Method in our first year program is that we believe its novelty is part of its effectiveness. Because of this, English 120 is the only course in the first year instruction program in which we use the method.

In addition to the benefits to the students, we have also found unexpected benefits to us as instructors: because we can't entirely predict the order in which we are presenting the material, we have become better at making explicit the connections between the concept we cover and the skills students need to learn. This has made us much more flexible in front of our classes, and able to better incorporate the authentic questions students ask (and are more likely to ask, thanks to the icebreaker function of the Cephalonian method) into the flow of the lesson. In one memorable session, after only two Cephalonian questions students began asking authentic (e.g., unscripted) questions and, thanks to our experience with the Cephalonian method, the session was able to be truly student driven while still covering the content of the session.

Using the Cephalonian method has allowed us to overcome the difficulties of moving to a more conceptual approach to information literacy in the first-year instruction program, as well as addressing challenges specific to flipped instruction. 
The Cephalonian Method is a viable instructional technique that can be readily adapted as needed to many contexts. We recommend this approach to librarians who are developing conceptually-oriented library sessions.

\section{References}

Barnes, C, \& Walton, E. (2007). Large-group induction at the University of Sussex Library: adapting the Cephalonian method. SCONUL Focus, Vol. 40, pp. 57-58.

Brown, C. and Hart, S. (2009), “'I had no idea that the Library has so much to offer!' The Cephalonian method of library induction: shaped by students, for students, and starring students!", LIANZA Conference, Christchurch, New Zealand. Retrieved from http://www.lianza.org.nz/sites/lianza.org. nz/files/CBrown_SHart_ Cephalonia_method.pdf, available at: http://www.lianza.org.nz/sites/default/files/cbrown_shart_cephalonia_method.pdf (accessed 2 February 2016).

Castle, C. and Acred, J. (2010), "Balfour \& Newton Libraries: Musings on using the Cephalonian method - a different method of teaching", Balfour \& Newton Libraries, 12 October, available at: https://balfourlibrary.blogspot.com/2010/10/musings-on-usingcephalonian-method.html (accessed 19 June 2016).

Galloway, L. (2010), “The Cephalonian Method of Instruction for First Year Science Undergraduates", available at: http://surface.syr.edu/cgi/viewcontent.cgi? article=1052\&context=nyscilib $($ accessed 22 June 2016). 
Hegarty, N. (2008), "Going Greek: introducing the Cephalonian method at WIT Libraries", Sconul Focus, Vol. 43, available at: http://repository.wit.ie/1429/1/Cephalonian.pdf (accessed 16 October 2015).

Jones, R., Peters, K. and Shields, E. (2007), “Transform your training: practical approaches to interactive Information Literacy teaching", Journal of Information Literacy, Vol. 1 No. 1, pp. $35-42$.

Kerr, P.A. (2010), Conceptions and Practice of Information Literacy in Academic Libraries: Espoused Theories and Theories-in-Use, Rutgers University-Graduate School-New Brunswick, available at: https://rucore.libraries.rutgers.edu/rutgers-lib/27317/ (accessed 21 June 2016).

Morgan, N. and Davies, L. (2004), "Innovative library induction-introducing the 'Cephalonian Method'.,, Sconul Focus, No. 32, pp. 4-8.

Morgan, N. and Davies, L. (2008), "How Cephalonia can conquer the world (or at the very least, your students!): A Library orrientation case study from Cardiff University”, in Cook, D. and Sittler, R.L. (Eds.), Practical Pedagogy for Library Instructors : 17 Innovative Strategies to Improve Student Learning, Association of College and Research Libraries, Chicago.

Oakleaf, M. (2014), “A Roadmap for Assessing Student Learning Using the New Framework for Information Literacy for Higher Education", The Journal of Academic Librarianship, Vol. 40 No. 5, pp. 510-514.

O’Flaherty, J. and Phillips, C. (2015), “The use of flipped classrooms in higher education: A scoping review", The Internet and Higher Education, Vol. 25, pp. 85-95. 
"Scary Stories to Tell in the Dark." (1995), Newsletter on Intellectual Freedom., Vol. 44 No. 5, p. 123.

Schwartz, A. (1981), Scary Stories to Tell in the Dark: Collected from American Folklore, Lippincott, New York.

Schwartz, A. and Zimmer, D. (1984), In a Dark, Dark Room, and Other Scary Stories, 1st ed., Harper \& Row, New York :

Seuss, D. (1960), Green Eggs and Ham, Beginner Books, New York.

Vossler, J. (2011), "Pirates of the Cephalonian Method", Humor and Information Literacy Practical Techniques for Library Instruction., ABC-CLIO, Santa Barbara, California, available at: Ebook Library http://public.eblib.com/choice/publicfullrecord.aspx?p=745312.

Wells, V. (2013), "Revising The Cephalonian Method”, ACRLog, 20 February, available at: http://acrlog.org/2013/02/20/revising-the-cephalonian-method/ (accessed 19 June 2016). 